\title{
Alberto Rebori, Stendhal a Milano
}

\section{Annalisa Bottacin}

\section{OpenEdition}

\section{Journals}

\section{Edizione digitale}

URL: http://journals.openedition.org/studifrancesi/6683

DOI: 10.4000/studifrancesi.6683

ISSN: 2421-5856

\section{Editore}

Rosenberg \& Sellier

\section{Edizione cartacea}

Data di pubblicazione: 1 septembre 2010

Paginazione: 385

ISSN: 0039-2944

\section{Notizia bibliografica digitale}

Annalisa Bottacin, «Alberto Rebori, Stendhal a Milano», Studi Francesi [Online], 161 (LIV | II) | 2010, online dal 30 novembre 2015, consultato il 13 janvier 2021. URL: http://journals.openedition.org/ studifrancesi/6683 ; DOI: https://doi.org/10.4000/studifrancesi.6683

Questo documento è stato generato automaticamente il 13 janvier 2021.

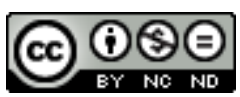

Studi Francesi è distribuita con Licenza Creative Commons Attribuzione - Non commerciale - Non opere derivate 4.0 Internazionale. 


\title{
Alberto Rebori, Stendhal a Milano
}

\author{
Annalisa Bottacin
}

\section{NOTIZIA}

ALBERTO REBORI, Stendhal a Milano, Biblioteca Comunale di Milano, Palazzo Sormani, 2006, pp. 63 , ill.

1 Collocato in una tendenza che sempre più va a espandersi anche nel nostro paese, quella del fumetto, lo Stendhal a Milano si compone di strisce che guardano in particolar modo a un pubblico giovanile, attraverso un linguaggio che agli adolescenti è quanto mai familiare e, nel caso specifico, inteso a facilitare in tal modo un approccio verso lo scrittore francese e la sua opera; il lavoro intende inoltre promuovere i preziosi materiali che il Centro Stendhaliano della Biblioteca Comunale Sormani di Milano conserva. Come si può ben desumere da un interessante articolo firmato da Yves-Marie Labé e apparso su «Le Monde des Livres» del 28 marzo 2008, la BD sta sempre più emergendo in Francia quale trasposizione d'opere letterarie, dopo il successo dei Misérables e del Voyage autour de la nuit, che rimonta al precedente ventennio. Ora, rileva Labé, «les adaptations dessinées d'œuvres littéraires se multiplient» (p. 9). Nel caso dello Stendhal a Milano è dunque visibile - a livello biografico - una nuova attenzione verso questa forma artistica, che giunge ora anche da alcune case editrici italiane che si sono inserite in quella scrittura d'arte che è il graphic novel, presentando un libro a immagini che dovrebbe maggiormente coinvolgere il pubblico, unendo alla lettura il fascino della pagina illustrata. Ma ritornando allo Stendhal di Rebori, che irrompe nella metropoli della modernità, non viene in lui certo meno, nella perseverante ammirazione per la città lombarda, il culto di essa, pur così straniante: Milano rimane luogo di attrazione senza limiti, città legata all'immenso amore mai vissuto e mantenuto vivissimo da Henri, per tutto il resto dell'esistenza, verso Métilde Viscontini Demboski, ispiratrice di tante eroine del tracciato scritturale stendhaliano.

2 «Cambiato il secolo e mutati i ruoli-scrive nella puntuale Nota all'edizione la responsabile del Centro Stendhaliamo Giulia Chiesa - nella seconda metà del '900 è il 
capoluogo lombardo che si fa protagonista di questo rapporto, quando accoglie la biblioteca dello scrittore francese rimasta, dal 1842 - anno della sua morte - al 1912, a Civitavecchia dove fu console di Francia» (p. 63). È un appassionato cultore di Stendhal, il noto fumettista Alberto Rebori che ha ideato la storia "moderna" del grenoblese e che ha voluto ridisegnarla, immergendolo in una realtà che lo stupisce, lo condiziona in quanto si muove sempre nel passato pur avvalendosi di reali e contingenti novità. Ma la chasse au bonheur è più che mai entusiasmante pur nei passaggi inconnus di una Milano diventata veloce, che si riscrive continuamente. Come ben sottolinea ancora Giulia Chiesa, il fumettista ha tracciato «una immaginaria promenade dans 1000 ans scandita da passi tratti da alcune sue opere [...] alla ricerca di persone, luoghi, sentimenti e atmosfere mai dimenticate. [...] Con questa storia fantastica narrata per immagini conclude Chiesa - il Centro Stendhaliano della Biblioteca Comunale ha voluto affidare anche al linguaggio del fumetto una affettuosa seppur insolita testimonianza di un rapporto iniziato nel lontano giugno del 1800 dal giovane Marie-Henri Beyle e non ancora concluso». 